\title{
Current status of acceptance and commitment therapy for chronic pain: a narrative review
}

This article was published in the following Dove Press journal: Journal of Pain Research

\author{
Albert Feliu-Soler ${ }^{1,2}$ \\ Francisco Montesinos 3,4 \\ Olga Gutiérrez-Martínez ${ }^{5}$ \\ Whitney Scott ${ }^{6}$ \\ Lance M McCracken ${ }^{6,7}$ \\ Juan $\mathrm{V}$ Luciano ${ }^{1,2}$ \\ 'Teaching, Research and Innovation \\ Unit, Parc Sanitari Sant Joan de \\ Déu, St. Boi de Llobregat, Spain; \\ 2Primary Care Prevention and \\ Health Promotion Research \\ Network (RedIAPP), Madrid, Spain; \\ ${ }^{3}$ Department of Psychology, Faculty \\ of Biomedical and Health Sciences, \\ Universidad Europea de Madrid, \\ Madrid, Spain; ${ }^{4}$ Instituto ACT, Madrid, \\ Spain; ${ }^{5}$ Fundación Biomédica Galicia \\ Sur, Vigo, Spain; ${ }^{6}$ Department of \\ Psychology, Institute of Psychiatry, \\ Psychology and Neuroscience, King's \\ College London, London, UK; ' INPUT \\ Pain Management, Guys and St \\ Thomas NHSFT, London, UK
}

\begin{abstract}
It is well known that chronic pain is prevalent, complex to manage, and associated with high costs, in health care and society in general. Thanks to advances in new forms of cognitive behavioral therapy (known as third-wave CBT), currently clinicians and researchers have an empirically validated psychological treatment with increasing research support for the treatment of chronic pain. This treatment is called acceptance and commitment therapy (ACT). The main aim of this paper is to provide a narrative review that summarizes and integrates the current state of knowledge of ACT in the management of chronic pain as well as discuss current challenges and opportunities for progress. Based on the psychological flexibility model, ACT extends previous forms of CBT and integrates many CBT-related variables into six core therapeutic processes. ACT is a process-based therapy that fosters openness, awareness, and engagement through a wide range of methods, including exposurebased and experiential methods, metaphors, and values clarification. To our knowledge, there are three published systematic reviews and meta-analyses that support the effectiveness of ACT for chronic pain and many studies focused on specific processes derived from the psychological flexibility model. There is also promising support for the cost-effectiveness of ACT; however, the current evidence is still insufficient to establish firm conclusions about cost-effectiveness and the most efficient means of delivery. Additional well-designed economic evaluations are needed. Other research aims include delineating the neurobiological underpinnings of ACT, refining available outcome and process measures or develop new ones for ACT trials, and meeting the challenge of wide dissemination and implementation in real-world clinical practice.
\end{abstract}

Keywords: acceptance and commitment therapy, chronic pain, review, assessment, clinical evidence, cost-effectiveness

\section{Introduction}

We must embrace pain and burn it as fuel for our journey. Kenji Miyazawa.

The purpose of the present narrative review is to provide an outline of the current state of ACT in the management of patients with chronic pain. This review is particularly timely given that ACT achieved the status of "well established" treatment for chronic pain according to the American Psychological Association. By documenting the theoretical standing, core processes, main measures, neurobiological underpinnings, and clinical and economic evidence for ACT, we will be in a better position to address the current gap between research findings and implementation of ACT in actual clinical
Correspondence: Juan $\mathrm{V}$ Luciano Teaching, Research and Innovation Unit, Parc Sanitari Sant Joan de Déu.C/ Doctor Antoni Pujadas 42, 08830 Sant Boi de Llobregat, Barcelona, Spain Tel +34936406350 ext I-2540 Email jvluciano@pssjd.org 
practice. We hope this review will provide the information necessary for shaping health-care policy regarding chronic pain management. Our narrative review is structured in eight main sections:

1. ACT background, description, and treatment techniques

2. ACT tools for measuring the six core processes

3. Empirical evidence of ACT for the management of chronic pain

4. Emerging evidence about the cost-effectiveness of ACT for chronic pain

5. Evidence for mediators and moderators of ACT for chronic pain

6. Hypothesized neurobiological mechanisms underlying ACT

7. Improving the implementation of ACT in health care systems

8. Future directions of ACT in chronic pain research

\section{ACT background, description, and treatment techniques}

$\mathrm{ACT}^{1}$ (said as one word not as letters) is a process-based, third-wave, cognitive behavioral therapy (CBT) that has shown its effectiveness in a broad set of psychological problems. ${ }^{2}$ ACT was not originally designed specifically to treat chronic pain, although this is the problem for which most of the current evidence has been found. ACT is grounded in a theory on language and cognition called "relational frame theory" and in functional contextualistic philosophy.

ACT approaches psychological problems in a dynamic context of social, verbal, emotional, and other direct sensory influences on behavior, with a particular emphasis on how suffering emerges predominantly within the uniquely human abilities in language and thought. Patients with chronic pain usually expend enormous effort in fighting against their experience of pain, which includes not only physical sensations but also emotions, memories, images, and thoughts about pain. They may reduce their physical activity, distract, avoid thoughts of pain or engage in excessive thoughts of pain, avoid other people, constantly check for bodily changes, ruminate about the causes of pain, complain, endlessly seek information, obsess over medications, or repeatedly request second opinions or additional medical care. This persistent behavior pattern aimed at searching for immediate relief and reducing physical and emotional discomfort has been called "destructive experiential avoidance" or "psychological inflexibility". ${ }^{3}$ Such avoidance of discomfort is usually followed in the short run by the reduc- tion of aversive stimulation, and therefore these behaviors are negatively reinforced. Not to mention that all of us have a learning history where solving problems by removing the problem has been successful. Nevertheless, experiential avoidance can lead to rebound effects, can reduce pain tolerance, and increases the severity of pain.,

It is only natural that if a person has pain, they will want it to stop, so natural in fact that to question this seems odd. Yet, at the same time, this goal is often unsuccessful and even counterproductive in direct experience. ${ }^{6}$ In contrast, the goal within ACT is to reduce the dominance of pain in person's life through increased psychological flexibility. Unlike other approaches, ACT does not focus on symptom reduction even though this can happen in ACT - but on making patients' responses toward symptoms more successful in relation to their own goals. This success is achieved through increases in psychological flexibility. Psychological flexibility is defined as the capacity to persist or to change behavior, including conscious and open contact with discomfort and other discouraging experiences, guided by goals and values. ${ }^{1}$ If the person has developed this ability, they will actively "accept" pain, in the sense of acting in line with their goals with experiences of pain or discomfort as a part of them.

Psychological flexibility is of course not just acceptance, it also includes five other core therapeutic processes, which are cognitive defusion, flexible present-focused attention, self-as-context, values, and committed action. These processes have been summarized as behavior that is open, centered or aware, and engaged. ${ }^{1}$ Acceptance is the ability to embrace unwanted experiences (pain, thoughts, feelings, memories, etc.) when they are connected to or a part of our goals. Cognitive defusion is being able to differentiate between thoughts and the experiences to which the thoughts relate. It includes experiencing thoughts as thoughts without getting stuck in their literal content. Flexible present-focused attention means being able to connect with the present moment and track moment-to-moment experience. Self-as-context is related to experiencing a distinction between the observed thoughts and feelings and the person who observes. Values are freely chosen directions connected with desired aims and goals that guide actions. Committed action is related with choosing a course of action guided by values and then persisting in this choice, or changing one's directions if they are no longer helpful. The six core processes of ACT are usually organized into what is referred to as a "hexaflex" (see Figure 1). The hexaflex is organized into three summary components: open (acceptance and defusion), aware (contact with the present and self-as-context), and engaged (values and committed action). 
Facets of psychological flexibility

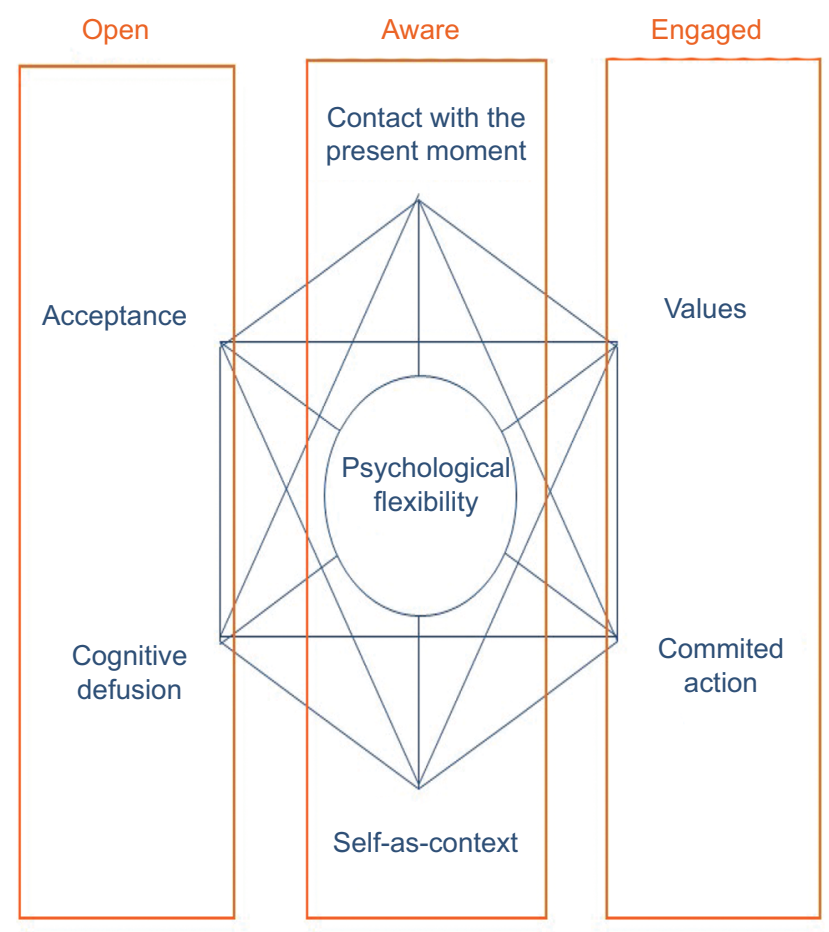

Figure I The hexaflex model of ACT for psychological flexibility and inflexibility. Abbreviation: ACT, acceptance and commitment therapy.

ACT is regarded as a process-based therapy, and thus it is the processes of psychological flexibility that represent the guiding tools during delivery. The treatment methods that follow from process choices included in ACT are primarily nondidactic and experiential, and include exposure-based methods, metaphor, paradox, and mindfulness-related exercises. ${ }^{7,8}$ Their use is always grounded in functional analysis and they are conducted in the context of a psychologically active therapeutic relationship. The primary intended outcome in ACT is improved daily functioning. ${ }^{9}{ }^{10}$ Treatment can be delivered individually or in a group format (an example of session by session outlines is shown in Table 1). Values assessment and clarification is an important part of ACT as success in reaching values-based goals is the determinant of successful treatment. Assessment of values-based goals is usually carried out to some degree at the beginning of treatment because it represents a guide within other methods. At the same time, values can be difficult, discouraging, or painful to clarify, so it is typically a process that continues throughout treatment. Yet another important part is the process of shifting perspective (also been labeled as "creative hopelessness"), which means collaboratively examining previous strategies to deal with problems to show how these strategies have or have not worked, particularly with respect to values and goals.

In ACT, participants typically see in their experience that turning away from pain and distress includes turning away from their values and goals, and the aim from there is to see if this process can be reversed. Then, participants are invited to affirm their values and goals, turn toward these, and open up to pain and distress as they do. Exposure to pain-eliciting situations, practically organized so that avoidance does not occur, can lead to an increase in values-directed behaviors and vice versa. In turn, defusion methods are aimed at seeing the content of thoughts in a different way, as separate from the events to which they refer and not essential to those events, as potential guides for action that can be followed or not. Defusion can be promoted through exercises and metaphors that include having participants changing the surface features of thoughts and responding differently to their own thought. This can include saying thoughts out loud, repeatedly and very fast, saying it softly or in a singing voice, looking at the thought as if it is someone else's, or to practically consider the question, "what happens when you follow what the thought says?" Each of these methods can disrupt the habitual experience and automatic influence exerted particularly by distressing or discouraging thoughts. In the next section we will focus on measure methods of the aforementioned six therapeutic processes.

Table I Example of session outlines for group-based ACT for chronic pain."

\begin{tabular}{ll}
\hline Session & ACT \\
\hline I & The limits of control (short- and long-term costs and benefits; finger traps), focus on experience (body scan) \\
2 & Values (what you care about, how you want to live your life) \\
3 & Cognitive defusion (observing thoughts without trying to evaluate or change them) \\
4 & Mindfulness (being in the moment) \\
5 & Committed action (connecting values, goals, actions, obstacles, and strategies) \\
6 & Review and continued action in support of values \\
7 & Review and continued action in support of values \\
8 & Moving forward \\
\hline
\end{tabular}

Abbreviation: ACT, acceptance and commitment therapy. 


\section{ACT tools for measuring the six core processes}

Since ACT is not aimed primarily at reducing psychopathological symptoms, changes in the nature and purpose of the assessment measures have been needed. Here, we focus on the most widely used ACT measures in the context of chronic pain.

The Psychological Inflexibility in Pain Scale ${ }^{12}$ is one of the scales employed for assessing psychological inflexibility in pain patients. Some studies have supported a two-factor solution (avoidance and cognitive fusion related to pain) with satisfactory psychometric properties. ${ }^{12-14}$ The avoidance factor reflects the behavioral tendency to withdraw from planned and valued activities and social participation in response to pain or its expectation (ie, "I do not do things that are important to me to avoid feeling my pain"). The fusion factor reflects entanglement of pain-related thoughts with actual experiences, or difficulty in distancing oneself from thoughts about the pain and its possible causes ("it is important to understand what causes my pain").

The Chronic Pain Acceptance Questionnaire (CPAQ) ${ }^{15}$ is a 20-item instrument assessing pain acceptance. It includes two subscales: activity engagement, which reflects performing desired activities in the presence of pain (ie, "I lead a full life even though I have chronic pain"), and pain willingness, which reflects the absence of attempts to control or reduce pain ("My thoughts and feelings about pain must change before I can take important steps in my life"; item reversed to reflect pain willingness). A systematic review of measures assessing acceptance of chronic pain concluded that the CPAQ demonstrates the highest performance in terms of its psychometric properties relative to other measures of pain acceptance ${ }^{16}$ Recently, an eight-item form (CPAQ-8) has been validated and shown to have good reliability in people with chronic pain. ${ }^{17}$ Also, there exists an adolescent-adapted version of the CPAQ. ${ }^{18}$

Besides pain acceptance, acceptance of psychological experiences outside of the pain itself, such as other undesirable physical symptoms, experiences of emotional distress, or distressing thoughts, has also been studied in chronic pain settings ${ }^{18}$ with the Acceptance and Action Questionnaire (AAQ-II). ${ }^{19}$ The AAQ-II is the most widely used measure of the construct referred to as, variously, acceptance, experiential avoidance, and psychological flexibility (depending on which way the items are scored), and it is a significant predictor of psychological functioning in a wide range of clinical and nonclinical samples. ${ }^{20}$
There are several measures to assess the process of cognitive defusion. In the context of chronic pain, the Cognitive Fusion Questionnaire (CFQ $)^{21}$ has been the most widely used. It was initially a 13-item scale with items keyed positively and negatively, ${ }^{22}$ and is now a seven-item scale with all items keyed in the direction of cognitive fusion. ${ }^{21}$ For instance, "My thoughts cause me distress or emotional pain" and "I get so caught up in my thoughts that I am unable to do the things that I most want to do". Evidence supports the reliability and validity of the CFQ for use among individuals with chronic pain. ${ }^{22}$

The process of flexible present-focused awareness has typically been assessed with different questionnaires that measure mindfulness. The most commonly used among people with chronic pain is the Mindful Attention Awareness Scale (MAAS). ${ }^{23}$ The MAAS is a 15 -item instrument measuring the general tendency to be attentive to and aware of one's experiences in daily life. Items include "I find myself preoccupied with the future or the past" or "It seems I am running on automatic without much awareness of what I'm doing." The MAAS has been shown to be a reliable instrument for measuring mindfulness in patients with chronic pain. ${ }^{24,25}$

Recently, a measure of self-as-context, the Self Experiences Questionnaire (SEQ), ${ }^{26}$ has also been validated in chronic pain samples ${ }^{27,28}$ and appears to be a reliable and valid measure of the self as defined within the psychological flexibility model. It is a 15-item questionnaire and examples of the items from this new measure include "Although I can get caught up in my thoughts, emotions and sensations, I can also separate from them"; "I can experience a distinction between my experiences and the 'I' who notices these experiences".

The Chronic Pain Values Inventory ${ }^{29}$ is a 12-item measure of engagement in valued activity for use with people with chronic pain. It asks respondents to rate the importance of the values they hold in six domains of living: family, intimate relations, friends, work, health, and growth or learning and their success at living according to them on a scale from 0 (not at all important/successful) to 5 (extremely important/successful), respectively. It has demonstrated adequate internal consistency and construct validity and sensitivity to change in ACT-based treatment for chronic pain..$^{29,30}$

Finally, the process of committed action in the context of chronic pain can also be reliably and validly measured by a self-report measure, the Committed Action Questionnaire (CAQ). ${ }^{31,32}$ There is a version of 18 items $^{31}$ and another of 8 items (CAQ-8). ${ }^{32}$ Examples of items include "I can remain committed to my goals even when there are times that I fail 
to reach them" or "I am able to follow my long terms plans including times when progress is slow". The CAQ and the CAQ-8 have satisfactory psychometric properties.

The growing number of choices of validated instruments for processes related to psychological flexibility allows assessing specific ACT treatment effects and mediators and moderators of change in people with chronic pain. This evidence will be reviewed in "Empirical evidence of ACT for the management of chronic pain" and "Evidence for mediators and moderators of ACT for chronic pain" sections.

\section{Empirical evidence of ACT for the management of chronic pain}

To date, three systematic reviews have been carried out on studies of ACT for patients with chronic pain. ${ }^{33-35}$ Overall, these reviews indicate that ACT can effectively lead to improved health outcomes. In 2014, Hann and McCracken ${ }^{33}$ systematically reviewed assessment approaches used in randomized-controlled trials (RCTs) of ACT for chronic pain in adults. Specifically, they wanted to identify the type of primary and secondary outcome domains assessed, to know the degree to which these domains reflected IMMPACT guidelines vs the theoretical model underlying ACT, to examine approaches to treatment process assessment in the trials, and finally, to make a narrative review of treatment efficacy. A total of 10 studies were included in their review. Most study measures were classified into domains in line with IMMPACT, including $70 \%$ and $60 \%$ of the studies for primary and secondary outcomes, respectively. Concerning risk of bias, the majority of the RCTs reviewed had an unclear risk of bias using an adapted Cochrane Collaboration tool. Two trials were judged as having a low risk, four were judged as having an unclear risk, and four were judged as having a high risk of bias. In general, ACT was not more effective than the "active" comparison conditions (eg, CBT) on most outcomes.

In 2016, Veehof et $\mathrm{al}^{34}$ conducted a meta-analysis of 28 studies to assess the effectiveness of acceptance and mindfulness-based interventions (MBIs; basically mindfulness-based stress reduction and mindfulness-based cognitive therapy) for chronic pain patients across RCTs. A total of 25 studies compared these interventions with waitlist, treatment as usual, or education/support groups, whereas five studies included active treatments as comparators. Taking passive control conditions as comparators, small posttreatment effects were found for pain intensity, depression, disability, and quality of life, and moderate effects were found for anxiety and pain interference. Concerning follow-up, the effect on pain increased but remained small, and the effects on depression and quality of life increased and became moderate. The effect on pain interference increased and became large. The effects on anxiety and disability remained moderate. Of interest is the result that ACT obtained a statistically significant higher mean effect on depression and anxiety than MBIs. When acceptance-based interventions and MBIs were compared to traditional CBT, the differences were not statistically significant.

More recently, Hughes et $\mathrm{al}^{35}$ have provided an update of the evidence for ACT in the treatment of patients with chronic pain. Eleven RCTs were included in their review. The authors confirmed the superiority of ACT when compared with passive control conditions (waitlist, usual care) for the improvement of both pain acceptance (medium-large effect size) and functioning (small effect size) as primary outcomes. Among the secondary outcomes, only psychological flexibility obtained a moderate-large effect size. Regarding the comparison with active treatments, ACT showed superiority over applied relaxation and expressive writing in some primary and secondary outcomes. In contrast, small differences in pooled SMDs were found on quality of life, depression, and pain intensity, in favor of CBT compared with ACT. In addition, the aforementioned positive findings should be tempered by some methodological shortcomings, such as the usual inclusion of small sample sizes, unclear adherence to treatment manuals, research allegiance, and the impossibility to blind participants to treatment allocation.

There are critics of ACT who claim that its development has not been accompanied by an increased methodological rigor. ${ }^{36}$ Öst concluded that when methodological problems are taken into account, ACT can be considered "probably efficacious" for pain conditions (and tinnitus) ${ }^{36}$ in contrast to the American Psychological Association (APA) Division 12 taskforce that indicates "strong research support" for chronic and persistent pain in general. Although the scientific rigor of this meta-analysis has been recently questioned by a panel of experts due to interpretation bias, ${ }^{37,38}$ it is desirable to overcome some of the methodological shortcomings of previous ACT trials highlighted by Öst to definitively inform policy-makers that ACT is a well-established psychological treatment for chronic pain management.

In recent years, the topic of dropouts from RCTs of psychological treatments has received burgeoning interest. ${ }^{39,40}$ It is perceived as a significant problem due to the loss of statistical power in research and because the patients' health needs are not being covered. ${ }^{39}$ A $15.8 \%$ dropout rate in RCTs of ACT has been recently reported (12.1\% in chronic 
pain and fibromyalgia), ${ }^{40}$ which is slightly better than that obtained by CBT $(25.3 \%)$ in the same meta-analysis. Altogether, the available empirical evidence indicates similar or slightly more effectiveness of traditional CBT compared with ACT at the expense of higher loss of patients over the course of therapy. A pending question in ACT, when specifically delivered to patients with chronic pain, is whether dropout rates vary as a function of certain variables such as therapy format (individual vs group), therapist experience (junior vs senior therapists), or chronic pain location or type. Currently, insufficient available data preclude these analyses.

\section{Emerging evidence about the cost- effectiveness of ACT for chronic pain}

Currently, both policy-makers and health-care professionals have to deal with financial pressures in a market-based environment. Clinicians are expected to administer costeffective treatments, particularly where health-care services are in part publicly funded, and the available resources are limited. The principle of cost-effectiveness is based on the idea that health-care decisions should be based on the costs of treatments in relation to health benefits for patients. ${ }^{41,42}$

Worldwide, mindfulness- and acceptance-based therapies are rapidly expanding and being applied in different contexts (hospitals, schools, companies, etc.), and there has been a call for more health economics research focused on psychological therapies in general ${ }^{43}$ and particularly in third-wave CBT. ${ }^{44}$ Though research in this area is in its infancy, recent evidence from economic evaluations of these therapies indicates that ACT might be a cost-effective treatment option for the management of chronic pain. ${ }^{44}$ As shown in Table 2, Kemani et al ${ }^{45}$ randomized Swedish adults with unspecific persistent pain to applied relaxation or ACT, both active treatments administered during 12 weeks, with pain disability as the primary outcome. Incremental cost-effectiveness ratios indicated that ACT was more cost-effective than applied relaxation after treatment and 3 months follow-up, but these findings did not remain significant at 6 months follow-up. More recently, Luciano et $\mathrm{al}^{46}$ tested the cost-utility of group ACT and found that eight 2.5 hour sessions were cost-effective for Spanish patients with fibromyalgia recruited in primary care centers compared with recommended pharmacological treatment (pregabalin plus duloxetine in cases of comorbid major depression), regardless of the type of analysis performed or the economic perspective (health-care system or societal). Therefore, in comparison to active psychological treatments (applied relaxation) and recommended medications, there are promising cost-effectiveness results for ACT in chronic pain patients.

Interest in economic evaluations of ACT is growing. As far as we know, there are two upcoming economic evaluations that will reinforce the available evidence about ACT for chronic pain. ${ }^{47,48}$ These ongoing economic evaluations alongside RCTs are summarized in Table 2.

Due to factors such as lack of available treatment providers, accessibility limitations, long waiting lists, and so on, and with the aim of reducing treatment costs, internetdelivered psychological treatments are becoming popular, and ACT is not an exception. Hayes et $\mathrm{al}^{47}$ are analyzing the cost-utility of an 8-week online ACT program for 152 patients with chronic pain compared to wait-list condition in Ireland. Unlike previous studies, the authors are using the relatively new version of the EuroQoL (EQ-5D-5L) instead of the classical one (EQ-5D-3L) with the expectation of increasing sensitivity to change. In a similar study conducted in Germany, ${ }^{48}$ the potential cost-utility of a guided (by trained eCoaches throughout the program) vs an unguided online ACT program (ActonPain) is being tested in adults with chronic pain. In contrast to the Irish study, this is a large confirmatory RCT (100 patients per study arm) with a longer follow-up (6 months), although these costeffectiveness results have not yet been published. There is clear need for further well-designed economic evaluations of ACT for chronic pain, including cost-effectiveness analyses embedded in RCTs.

\section{Evidence for mediators and moderators of ACT for chronic pain}

The evidence for the effectiveness of ACT in the management of chronic pain is essentially established, as we have shown above. However, relatively little is understood about how (ie, mediators) and for whom (ie, moderators) therapeutic change occurs. As an acknowledged process-based therapy, ACT arguably emphasizes these perhaps more than other versions of CBT, which might be more protocol or method based. Mediators and moderators are important to improve clinical decisions and to further optimize the (cost-)effectiveness of ACT. ${ }^{49,50}$ Both nonspecific and specific treatment mediators or moderators of ACT indicate who benefits from treatment, or under which conditions ACT pain interventions works best. Next, evidence for mediators, firstly, and moderators, secondly, is reviewed.

One RCT evaluating ACT in chronic whiplash-associated disorder showed that positive changes in pain-related disability and life satisfaction were mediated by reductions in 
Table 2 Published and upcoming (data extracted from study protocols) economic evaluations of ACT for chronic pain

\begin{tabular}{|c|c|c|c|c|c|c|}
\hline $\begin{array}{l}\text { Author } \\
\text { Year } \\
\text { Country }\end{array}$ & $\begin{array}{l}\text { Target } \\
\text { condition }\end{array}$ & $\begin{array}{l}\text { Treatment arms }(n) ; \\
\text { Delivery period }\end{array}$ & $\begin{array}{l}\text { Cost categories included } \\
\text { (cost-perspective) }\end{array}$ & $\begin{array}{l}\text { Clinical } \\
\text { effect or } \\
\text { utility } \\
\text { outcome }\end{array}$ & $\begin{array}{l}\text { Results of the economic } \\
\text { evaluation }\end{array}$ & $\begin{array}{l}\text { Time } \\
\text { horizon }\end{array}$ \\
\hline $\begin{array}{l}\text { Kemani } \\
\text { et a }\left.\right|^{45} \\
2015 \\
\text { Sweden }\end{array}$ & $\begin{array}{l}\text { Unspecific, } \\
\text { long-standing } \\
\text { pain }\end{array}$ & $\begin{array}{l}\text { ACT }(n=30) \\
\text { AR }(n=30) \\
\text { Delivery period: } 12 \text { weeks }\end{array}$ & $\begin{array}{l}\text { Analysis from the societal } \\
\text { perspective. Data obtained in } \\
\text { three different domains: (I) direct } \\
\text { medical costs, comprising costs } \\
\text { related to health-care utilization, } \\
\text { medication use + intervention } \\
\text { costs; ( } 2 \text { ) direct nonmedical costs; } \\
\text { and (3) indirect nonmedical costs } \\
\text { (employment status, sick leave, } \\
\text { and reduced capacity at work and } \\
\text { domestically). }\end{array}$ & PDI & $\begin{array}{l}\text { Cost-effectiveness (ITT; } \\
\text { societal perspective) } \\
\text { ICER at } 6 \text { months not } \\
\text { reported. No differences in } \\
\text { costs or effectiveness between } \\
\text { the two treatments. } \\
\text { ICER ( } 3 \text { months) = } \\
\text { - \$648. Each incremental } \\
\text { improvement on the PDI for } \\
\text { ACT participants relative to } \\
\text { AR yielded a societal earning } \\
\text { of } \$ 648 \text { at } 3 \text { months. }\end{array}$ & 6 months \\
\hline $\begin{array}{l}\text { Luciano } \\
\text { et al }\left.\right|^{46} \\
2017 \\
\text { Spain }\end{array}$ & Fibromyalgia & $\begin{array}{l}\text { ACT }(n=5 I) \\
\text { RPT }(n=52) \\
\text { WL }(n=53) \\
\text { Delivery period: } 8 \text { weeks }\end{array}$ & $\begin{array}{l}\text { Analyses performed from the } \\
\text { health care (self-reported data } \\
\text { collection about medication } \\
\text { consumption, medical tests, use } \\
\text { of health-related services, and } \\
\text { cost of the staff running the ACT } \\
\text { intervention) and from a restricted } \\
\text { societal perspective (productivity } \\
\text { losses). }\end{array}$ & EQ-5D-3L & $\begin{array}{l}\text { Cost-utility analysis (ITT; } \\
\text { societal perspective) } \\
\text { ICURs not reported. ACT was } \\
\text { found to be dominant when } \\
\text { compared against RPT and } \\
\text { WL. The average incremental } \\
\text { cost for the comparison ACT } \\
\text { vs RPT was } € 389.5 \text {. The } \\
\text { incremental effect for QALYs } \\
\text { was found to be around } 0.0 \text { I. }\end{array}$ & 6 months \\
\hline $\begin{array}{l}\text { Hayes et } \\
\text { al }^{47} \\
2014 \\
\text { Ireland }\end{array}$ & $\begin{array}{l}\text { Nonmalignant } \\
\text { chronic pain }\end{array}$ & $\begin{array}{l}\text { Internet-delivered ACT } \\
(\mathrm{n}=76) \\
\text { Waitlist control (are } \\
\text { offered the ACT } \\
\text { intervention after the } 3 \\
\text { months follow-up period) } \\
\text { ( } \mathrm{n}=76) \\
\text { Delivery period: } 8 \text { weeks }\end{array}$ & $\begin{array}{l}\text { Societal perspective. Health } \\
\text { service use (primary health-care } \\
\text { consultations, hospital visits, } \\
\text { etc.) and medication use, which } \\
\text { is likely to vary throughout the } \\
\text { RCT duration, therefore change } \\
\text { in medication use (prescribed and } \\
\text { over-the-counter) is measured in } \\
\text { posttreatment analysis. Record } \\
\text { of nonmedical costs related to } \\
\text { out-of-pocket expenses (on any } \\
\text { treatment not paid by the state, } \\
\text { the costs of traveling to, and wait } \\
\text { times at, the various health-care } \\
\text { services). Costs associated with } \\
\text { taking time off work or reduced } \\
\text { employment for the patient } \\
\text { with chronic pain or for family } \\
\text { members who care for the patient. }\end{array}$ & $\begin{array}{l}\text { EQ-5D-5L } \\
\text { BPI }\end{array}$ & Upcoming & 列 \\
\hline $\begin{array}{l}\text { Lin et al }{ }^{48} \\
2015 \\
\text { Germany }\end{array}$ & Chronic pain & $\begin{array}{l}\text { Guided ACT-based online } \\
\text { intervention ("ACTonPain" } \\
\text { program); support of an } \\
\text { eCoach ( } \mathrm{n}=100 \text { ) } \\
\text { Unguided ACT-based online } \\
\text { intervention ("ACTonPain" } \\
\text { program; } \mathrm{n}=100 \text { ) } \\
\text { Waitlist control (participants } \\
\text { receive intervention (b) } 6 \\
\text { months after the start of the } \\
\text { intervention; } n=100 \text { ) } \\
\text { Delivery period: } 7 \text { weeks }\end{array}$ & $\begin{array}{l}\text { Societal perspective. Direct } \\
\text { and indirect costs are assessed: } \\
\text { participants register direct } \\
\text { costs (eg, health service uptake } \\
\text { or medication). Indirect costs } \\
\text { - number of "work loss" days } \\
\text { (absenteeism from work) and the } \\
\text { number of "work cut-back" days } \\
\text { (reduced productivity at work) }\end{array}$ & EQ-5D-3L & Upcoming & 6 months \\
\hline
\end{tabular}

Abbreviations: ACT, acceptance and commitment therapy; AR, applied relaxation; BPI, brief pain inventory; EQ-5D, European Quality of Life (EuroQol) instrument ( $3 \mathrm{~L}=$ three-level version; $5 \mathrm{~L}=$ five-level version); ITT, intent to treat; PDI, Pain Disability Index; RCT, randomized-controlled trial; QALY, quality-adjusted life years; RPT, recommended pharmacological treatment; WL, waiting-list; ICER, Incremental cost-effectiveness ratio; ICUR, Incremental cost-utility ratio.

Source: Adapted from Feliu-Soler et al ${ }^{44}$ 
a measure of psychological inflexibility rather than change in potentially competing processes, including fear of movement and self-efficacy. ${ }^{51}$ In addition, several controlled and uncontrolled trials have shown significant changes in individual components of psychological flexibility (acceptance, cognitive defusion, values-based action, present-focused awareness, self as observer, and committed action) after interdisciplinary ACT treatments for chronic pain, although the strength of the empirical support is not equal for all these components. ${ }^{33,52-54}$

Research to date has predominantly focused on the processes of pain-related acceptance and values-based action. Acceptance and values-based action are associated with better functioning in individuals with chronic pain. ${ }^{55-57}$ There are also data showing that acceptance and valuesbased action improve in treatment based on ACT and these improvements are associated with improvements on diverse outcome measures..$^{9,30,58,59}$ Concerning the interactions between these two processes, it seems that the relative time course of changes is an important question. Data suggest that acceptance dominates in the prediction of posttreatment outcomes, whereas values-based action dominates in predicting follow-up outcomes. ${ }^{30}$ Nevertheless, interactions between the different processes of psychological flexibility over the course of the therapy and during follow-up phases deserve further research. Other interesting findings highlight the role of pain-related acceptance as an important treatment process even when not explicitly targeted during treatment. Åkerblom et al ${ }^{60}$ demonstrated that pain-related acceptance, on its own, significantly partially mediated changes in outcome measures during a CBT-based treatment program, even when other potential CBT process variables were taken into account.

Even the least well-recognized processes of psychological flexibility now have some empirical support, including present-focused awareness, cognitive defusion, self-asobserver, and committed action. This research is possible thanks to the development of sound measures of these processes in people with pain, as discussed earlier. ${ }^{22,26,32} \mathrm{As}$ predicted, data indicate that these measures are associated with emotional well-being and general daily functioning in cross-sectional analyses. ${ }^{25,61}$ In addition, several prospective treatment outcome studies explicitly address defusion, self-as-observer, and committed action, and the pattern of results is also functionally consistent with the underlying model. ${ }^{62-64}$

As we have seen before, there are a number of valid measures of ACT processes and it is clear that these measures are strongly related to various aspects of patient functioning and usually account for a noteworthy amount of variance above and beyond other pain-related symptoms or cognitions. However, the interrelationships among these single measures are not so clear. To date, only two studies have undertaken comprehensive examinations of the factor structure of measures of psychological flexibility processes. ${ }^{65,66}$ Both the studies show that the component processes of ACT model, collectively considered, appear highly relevant to important aspects of patient functioning in chronic pain. Although the structure of the data differed slightly, both studies' findings are concordant with recent accounts of psychological flexibility in terms of three dyadic processes: open, aware, and engaged ${ }^{67}$ Further research is necessary to better clarify whether the overarching process of psychological flexibility can be usefully distilled into fewer than six distinct subprocesses and thus potentially facilitate a more useful, or "userfriendly", understanding of how this process is implicated in chronic pain and its recovery.

Research on ACT moderators (baseline characteristics that interact with treatment to affect outcome) and nonspecific predictors (baseline characteristics that do not interact with treatment, but predict outcome regardless of treatment) for chronic pain is still in its infancy. The effects of ACT generally do not vary according to sociodemographic characteristics. ${ }^{9}$ These findings are consistent with previous CBT studies that have generally failed to find reliable relationships between patient outcomes and demographic variables. ${ }^{68}$

There is some low-quality evidence that longer pain duration $^{30}$ or higher disability ${ }^{69}$ might lead to greater improvements in face-to-face ACT interventions for chronic pain. In one of the few RCTs designed primarily to compare ACT and CBT moderators for chronic pain, it was found that older adults were more likely to respond to ACT, whereas younger adults were more likely to respond to CBT. ${ }^{70}$ These data generally support previous indications that ACT may be particularly appropriate and acceptable for those who have experienced a greater number of failed efforts to reduce their pain. These results are also consistent with the literature about moderators in MBIs, where there is some evidence that higher psychological distress or history of depression may predict better outcomes. ${ }^{71}$ However, it is convenient to be cautious. As the only systematic review for predictors in contextual cognitive and behavioral therapies for chronic pain show, important methodological limitations exist in this area of research, and for most predictors the evidence is inconclusive because of the small number of studies investigating each predictor or inconsistent findings between 
several studies. ${ }^{72}$ Thus, only limited progress has been made in understanding which specific patient-level characteristics make someone with chronic pain a particularly good or poor candidate for ACT. Optimistically, ACT benefits diverse chronic pain patients across a range of sociodemographic factors, and at least in one study, ACT outperforms CBT for older adults.

\section{Hypothesized neurobiological mechanisms underlying ACT}

Within ACT, targeting neurobiological mechanisms is not seen as a goal of treatment. Nonetheless, it may be useful to consider the relationship between ACT, psychological flexibility, and neurobiological processes to more fully appreciate the context and wider field of chronic pain research.

Although there is a striking lack of studies including neurobiological markers as process or outcome variables in ACT research, there are some interesting findings that merit mentioning in this section. In this regard, in a study performed by Jensen et al, ${ }^{73} 43$ women with fibromyalgia were randomly allocated to a 12-week group-based form of $\operatorname{ACT}(n=25)$ or to waiting list $(n=18)$, with brain activation to pressure-evoked pain (with fMRI) assessed before and after treatment. As ACT promotes openness to emotions, thoughts, and bodily sensations, this study was focused on prefrontal cortex which is mainly involved in cognitive control. Along with some clinical improvements (ie, patient global impression of change, depression, and anxiety), increases in activation in the ventrolateral prefrontal/lateral orbitofrontal cortex were found after ACT. This change in activation was also correlated with marginally significant changes in anxiety. Neither the subjective impression of clinical change nor changes in depressive symptoms correlated significantly with brain activation in either of the two groups. Additionally, an increased pain-evoked connectivity between the vlPFC and thalamus after ACT was also observed, suggesting treatment-related changes in crucial nodes of pain modulation.

In a recent pilot study, ${ }^{74}$ effects of a 4 -week chronic pain-focused ACT intervention $(n=6)$ vs health education program $(n=6)$ on pain-related activation and in resting state connectivity between pain regions and the default mode network (DMN) were evaluated in patients with chronic pain and opioid addiction. After treatment, patients allocated to ACT exhibited significant decreases in activation in face of evoked pain compared with controls in the middle frontal gyrus, inferior parietal lobule, insula, anterior cingulate cortex, posterior cingulate cortex, and superior temporal gyrus. Pre-post changes in resting state connectivity in the ACT group, and also in comparison to control group at posttreatment, were observed. In this regard, patients allocated to ACT showed an overall decreased connectivity between pain processing areas and DMN. Reduced activation of pain-processing brain areas may indicate a beneficial effect of ACT on brain's responsiveness to painful stimuli in patients with comorbid chronic pain and opioid addiction. As the ACT group showed decreased resting connectivity at posttreatment and these changes were stronger in DMN function than in the pain network, it is speculated that positive effects of ACT may be mainly due to its effect on altering DMN than in changing the connectivity between pain-processing areas.

$\mathrm{ACT}$ and MBIs share some practices and mechanisms. ${ }^{75}$ In this vein, one might tentatively hypothesize that both therapeutic approaches may share similar effects at the neurobiological level. Regarding this point, several studies have reported changes indicative of greater emotion regulation and increased tolerability to pain after MBIs. Structural changes in specific brain areas (eg, hippocampus, posterior cingulate cortex, the temporo-parietal junction, and cerebellum) have been reported after an MBI. ${ }^{76}$ Additionally, functional brain changes (eg, higher activity in left frontal activation, insula, secondary somatosensorial cortex, and in anterior cingulate cortex, and lower activity in right amygdala and in several DMN regions) have also been observed after standard MBIs. ${ }^{77}$ These affected areas are related to enhanced learning and memory processes, emotion regulation, self-referential processing, perspective taking, increased present-focused mode of self-reference, higher interoceptive awareness, more accurate processing of exteroceptive sensory events, higher attentional control, and reduced conceptual processing. Regarding effects on pain experience, short mindfulness trainings seem to promote lower pain unpleasantness and intensity ratings (compared with resting state) in face of a painful stimulation. Such changes in pain perception were found to be related to an increased activity in brain areas of cognitive and affective regulation of nociceptive processing (anterior cingulate cortex and insula), reframing the contextual evaluation of sensory events (orbitofrontal cortex), and changes in the interaction between afferent input and executive-order brain areas (reduction of thalamic activity). ${ }^{78,79}$ In order to better understand how ACT works, further studies might incorporate neurobiological markers as outcome variables in RCTs. We have identified one ongoing study that may shed more light on the biological underpinnings of ACT. ${ }^{80}$ 


\section{Improving the implementation of ACT in health care systems}

Although there is room for improvement and there are remarkable cross-country differences, ACT has been implemented in public care for patients with chronic pain in some countries. In 2011, the Institute of Medicine issued a report on pain care in the United States stating that multimodal, therapeutic approaches based on the biopsychosocial model and promoting patients' self-management skills are the optimal paradigms for improving the effectiveness of chronic pain management. ${ }^{81}$ This report also highlighted that chronic pain treatment usually excludes evidence-based nonpharmacological treatments (NPT) and are frequently pharmacological only, ${ }^{82}$ despite this approach being suboptimal and, potentially, unsafe. ${ }^{81,83}$ To identify why NPT are poorly implemented in practice in chronic pain management, Becker et al ${ }^{84}$ determined barriers and facilitators from patients, nurses, and primary care providers' perspectives. For patients, high costs, low motivation, and transportation issues were the main barriers to use NPT. On the other hand, in relation to providers, the main barriers included inability to promote NPT once opioid therapy was initiated and patient's skepticism about efficacy of these approaches.

As stated before, from the patients' perspective, many individuals with chronic pain have mobility limitations and financial restrictions that make travel difficult. ${ }^{85}$ This may constitute one barrier for implementation inherent to any psychotherapeutic approach, including ACT, related to the relatively high frequency of sessions needed to make the treatment effective. To overcome this barrier, several variations to the standard protocol can be done as ACT can be applied in briefer forms ${ }^{86}$ and, along with the global expansion of Internet, web-based interventions based on ACT have emerged. In this regard, there is promising evidence in the field of telehealth and internet-delivered ACT, which may overcome this limitation, especially for individuals living with chronic pain in rural areas. ${ }^{87-90}$

One additional barrier for implementation of ACT is limited availability of certified/specialized professionals. Training in ACT often requires personal experiential practice aimed at improving therapist psychological flexibility. This may require consistent practice and often continuing supervision to produce long-term change in professionals' behavior, and not only learning third-wave techniques. ACT holds that therapists need to be psychologically flexible in order to effectively use these techniques. Some research support this assertion, such that therapists who are less psychologically flexible may model and reinforce the opposite psychological inflexibility, which opposes the aims of ACT. ${ }^{91}$ Competencies of an ACT therapist include compassion, vulnerability, a sharing point of view, ability to be flexible to suit the needs of the individual/group, and where appropriate, to self-disclose as well as be open to challenging content. ${ }^{92}$

Regarding how to find a strategic plan to overcome the barrier of knowledge in ACT by disseminating knowledge on ACT multidisciplinary professionals at pain rehabilitation centers, some recent successful endeavors on implementing it on a national scale have been recently carried out. ${ }^{93} \mathrm{~A}$ systematic implementation of ACT in Dutch chronic pain rehabilitation centers was rolled out over 18 months applying a multifaceted, interactive training program with coaching sessions and feedback, using a train-the-trainer approach, using ad-hoc materials developed to help guidance and adherence to ACT principles. Professionals received education on ACT while in the meantime they were applying ACT in their daily work. Changes in multidisciplinary professionals' self-perceived competencies in working with ACT were evaluated and corroborated with patients' ratings of treatment adherence with very positive results.

In a similar way to other third-wave CBTs, a large-scale strategic implementation plan for ACT may benefit from concepts such as "stepped-care" and "low intensity-high volume" interventions that may allow for greater flexibility and easier access to different ACT-based interventions in health care services at national, regional, and local levels. ${ }^{94,95}$ An alternative is to apply a stratified approach, based on assessment of risk or prognostic factors, or complexity, and assign levels of treatment intensity accordingly. ${ }^{96}$

\section{Future directions of ACT in chronic pain research}

Taken as a whole, the research discussed demonstrates important advancements in the state of evidence for ACT and the psychological flexibility model as applied to chronic pain. Of course, there is still progress to be made. Questions to guide future research here are similar to those that remain for other psychological approaches to pain management and, indeed, the field at large: what works for whom, how, and under which circumstances. ${ }^{97-99}$

The issue of "what works for whom", or treatment moderators, is likely complex. Given the identified challenges in examining sociodemographic factors as moderators, it might be fruitful to use a more theoretically driven approach. For 
example, future research might investigate whether baseline levels of psychological flexibility moderate treatment effect. If moderators are identified in this way, we could subsequently select participants for treatment on the basis of scores on key process measures. An extension of this is to examine whether certain delivery formats may be better suited to patients with different levels of psychological flexibility. For example, it may be that remote delivery is better suited for those with relatively higher psychological flexibility, while more intensive, face-to-face and residential treatments may be required for those with low levels of psychological flexibility.

One area of developing interest is the evaluation of psychological approaches like ACT to specific chronic pain conditions, such as those occurring in the context of other medical comorbidities. Although it is generally assumed that ACT (and other psychological approaches) applies across pain types, this requires testing. Neuropathic pain represents an area of particular opportunity here given that only two RCTs of psychological treatments have been conducted in this population. ${ }^{100}$ For example, the transdiagnostic focus within ACT may be well suited to efficiently address the multitude of symptoms and behavioral challenges faced by people with HIV- or diabetes-related painful peripheral neuropathy. In addition to pain, these conditions may be accompanied by stigma, shame, fears of disease progression and death, grief, nonadherence to medical treatment regimens, and so on. The impact of these challenges on functioning and quality of life may be underpinned by processes of psychological (in)flexibility. ${ }^{101-105}$

Our ability to test mediators of ACT treatment effects will likely require refinements of existing measures of psychological flexibility. Such refinements are needed to ensure that measures reliably and validly capture core facets of psychological flexibility while minimizing redundancy across measures. ${ }^{65}$ To this end, the recent development of the CompACT tool, which efficiently assesses core processes of psychological flexibility and shows good convergent and discriminant validity, may prove useful. ${ }^{106}$ Much of the research on processes of ACT for chronic pain to date has been done using pre- and posttreatment/follow-up designs. This limits our ability to more sensitively determine the time course of changes in ACT processes and corresponding mediation effects. A potentially impactful development in research on psychological flexibility could be the use of frequent sampling of psychological flexibility processes, through methods such as ecological momentary assessment. ${ }^{107,108}$ The application of these developments to ACT research in chronic pain will require further validation of brief assessment tools of psychological flexibility and primary pain outcomes (eg, pain interference and daily functioning) for repeated use. Greater understanding of the processes underlying ACT treatment effects and the time course of these will enable greater precision of targeting these processes. Lastly, there is evidence that treatment outcomes and processes, such as pain acceptance, change to a similar extent in "third-wave" approaches and traditional CBT for pain. ${ }^{109}$ Therefore, future research may shift focus away from directly comparing these two approaches, and instead focus on determining how to best target core processes across treatments (ie, "process-focused therapy"). ${ }^{110}$ This change in strategy may require a shift away from using RCTs, to other designs that may address the challenge at hand more effectively, such as single case designs. ${ }^{111}$

In the context of increasing burdens placed on health-care systems worldwide, there is clearly a need for accessible and cost-effective ACT delivery methods. Within face-to-face methods, the training of outpatient rehabilitation professionals, such as physiotherapists, to deliver brief forms of ACT with minimal training may be a useful strategy to increase access moving forward. ${ }^{112}$ This approach may efficiently capitalize on the multidisciplinary approach, which is so important for managing chronic pain.

As mentioned, internet delivery of ACT for chronic pain is an area of growing interest with the potential to increase cost-effectiveness. Beyond these benefits, digital technology may be used to enhance delivery of ACT, either in isolation or as a complement to traditional face-to-face delivery. ${ }^{113}$ For example, e-health interventions can provide ample opportunity for tracking, shaping, and reinforcing processes of psychological flexibility in participants' daily lives through frequent reminders and real-time feedback. Such tracking can be used to orient participants to experiential exercises and metaphors that may be particularly relevant to their inthe-moment scores on psychological flexibility processes.

Much progress has been made in the development and evaluation of ACT for chronic pain over the past decade. There remains important work to do to optimize our assessment tools, treatment technology, and implementation procedures. As ever, flexibility may be a key as we move forward, both in our approach to empirical progress and clinical innovation.

\section{Key points of this review}

- An outline of the empirical status of acceptance and commitment therapy (ACT) in the treatment of chronic pain and main challenges faced by clinicians and researchers in the field are provided. 
- The psychological flexibility model with its broad focus on cognitive, emotional, social, and motivational factors is considered a helpful guide for generating progress in ACT.

- The clinical effectiveness of ACT for the management of chronic pain is well established, but other areas such as the cost-effectiveness or neurobiological underpinnings of ACT are still in its infancy. Further research on these topics seems warranted.

\section{Acknowledgments}

AFS has a "Sara Borrell" research contract from the Instituto de Salud Carlos III (ISCIII) (CD16/00147). This manuscript is an independent work partly supported by the National Institute for Health Research (NIHR Postdoctoral Fellowship, Dr Whitney Scott, PDF-2015-08-059). LMM is partly funded by the National Institute for Health Research (NIHR) Biomedical Research Center at South London and Maudsley NHS Foundation Trust and King's College London in the UK. The views expressed are those of the authors and not necessarily those of the NHS, National Institute for Health Research, or the Department of Health. JVL has a "Miguel Servet" research contract from the ISCIII (CP14/00087). We are also grateful to the Network for Prevention and Health Promotion in Primary Care (RD16/0007/0012) for its financial support.

\section{Disclosure}

The authors report no conflicts of interest in this work.

\section{References}

1. Hayes SC, Strosahl KD, Wilson KG. Acceptance and Commitment Therapy: An Experiential Approach to Behaviour Change. New York: Guilford Press; 1999.

2. Ruiz FJ. A review of Acceptance and Commitment Therapy (ACT) empirical evidence: correlational, experimental psychopathology, component and outcome studies. Int J Psychol Psychol Ther. 2010;10:125-162.

3. Hayes SC, Wilson KG, Gifford EV, Follette VM, Strosahl K. Experiential avoidance and behavioral disorders: a functional dimensional approach to diagnosis and treatment. J Consult Clin Psychol. 1996;64(6):1152-1168.

4. Goubert L, Crombez G, Eccleston C, Devulder J. Distraction from chronic pain during a pain-inducing activity is associated with greater post-activity pain. Pain. 2004;110(1):220-227.

5. Masedo AI, Rosa Esteve M, Esteve MR. Effects of suppression, acceptance and spontaneous coping on pain tolerance, pain intensity and distress. Behav Res Ther. 2007;45(2):199-209.

6. Mccracken LM, Montesinos-Marín F. Current and future trends in psychology and chronic pain: time for a change? Pain Manag. 2014;4(2):113-121.

7. McCracken LM. Contextual Cognitive-Behavioral Treatment for Chronic Pain. Seattle: IASP Press; 2005.

8. Dahl J, Wilson KG, Luciano MC, Hayes SC. Acceptance and Commitment Therapy for Chronic Pain. Reno: Context Press; 2005.
9. Mccracken LM, Gutiérrez-Martínez O. Processes of change in psychological flexibility in an interdisciplinary group-based treatment for chronic pain based on acceptance and commitment therapy. Behav Res Ther. 2011;49(4):267-274.

10. Wicksell RK, Melin L, Olsson GL. Exposure and acceptance in the rehabilitation of children and adolescents with chronic pain. Eur $J$ Pain. 2007;11:267-274.

11. Wetherell JL, Afari N, Rutledge T, et al. A randomized, controlled trial of acceptance and commitment therapy and cognitive-behavioral therapy for chronic pain. Pain. 2011;152(9):2098-2107.

12. Wicksell RK, Renöfält J, Olsson GL, Bond FW, Melin L. Avoidance and cognitive fusion - central components in pain related disability? Development and preliminary validation of the Psychological Inflexibility in Pain Scale (PIPS). Eur J Pain. 2008;12(4):491-500.

13. Rodero B, Pereira JP, Pérez-Yus MC, et al. Validation of a Spanish version of the Psychological Inflexibility in Pain Scale (PIPS) and an evaluation of its relation with acceptance of pain and mindfulness in sample of persons with fibromyalgia. Health Qual Life Outcomes. 2013;11(1):62.

14. Wicksell RK, Lekander M, Sorjonen K, Olsson GL. The Psychological Inflexibility in Pain Scale (PIPS) - statistical properties and model fit of an instrument to assess change processes in pain related disability. Eur J Pain. 2010;14(7):771.e1-771.e14.

15. Mccracken LM, Vowles KE, Eccleston C. Acceptance of chronic pain: component analysis and a revised assessment method. Pain. 2004;107(1):159-166.

16. Reneman MF, Dijkstra A, Geertzen JHB, Dijkstra PU. Psychometric properties of Chronic Pain Acceptance Questionnaires: a systematic review. Eur J Pain. 2010;14(5):457-465.

17. Mccracken LM, Gauntlett-Gilbert J, Eccleston C. Acceptance of pain in adolescents with chronic pain: validation of an adapted assessment instrument and preliminary correlation analyses. Eur J Pain. 2010;14(3):316-320.

18. Mccracken LM, Zhao-O'Brien J. General psychological acceptance and chronic pain: there is more to accept than the pain itself. Eur $J$ Pain. 2010;14(2):170-175.

19. Bond FW, Hayes SC, Baer RA, et al. Preliminary psychometric properties of the Acceptance and Action Questionnaire-II: a revised measure of psychological inflexibility and experiential avoidance. Behav Ther. 2011;42(4):676-688.

20. Hayes SC, Luoma JB, Bond FW, Masuda A, Lillis J. Acceptance and commitment therapy: model, processes and outcomes. Behav Res Ther. 2006;44(1):1-25.

21. Gillanders DT, Bolderston H, Bond FW, et al. The development and initial validation of the Cognitive Fusion Questionnaire. Behav Ther. 2014;45(1):83-101.

22. Mccracken LM, Dasilva P, Skillicorn B, Doherty R. The Cognitive Fusion Questionnaire: a preliminary study of psychometric properties and prediction of functioning in chronic pain. Clin J Pain. 2014;30:8 94-901.

23. Brown KW, Ryan RM. The benefits of being present: mindfulness and its role in psychological well-being. J Pers Soc Psychol. 2003;84(4):822-848.

24. Cebolla A, Luciano JV, Demarzo MP, et al. Psychometric properties of the Spanish version of the mindful attention awareness scale (MAAS) in patients with fibromyalgia. Health Qual Life Outcomes. 2013; 11(1):6.

25. Mccracken LM, Gauntlett-Gilbert J, Vowles KE. The role of mindfulness in a contextual cognitive-behavioral analysis of chronic painrelated suffering and disability. Pain. 2007;131(1):63-69.

26. Yu L, Mccracken LM, Norton S. The Self Experiences Questionnaire (SEQ): preliminary analyses for a measure of self in people with chronic pain. J Contextual Behav Sci. 2016;5(3):127-133.

27. Yu L, Norton S, Mccracken LM. Change in "Self-as-Context" ("perspective-taking") occurs in acceptance and commitment therapy for people with chronic pain and is associated with improved functioning. J Pain. 2017;18(6):664-672. 
28. Yu L, Norton S, Almarzooqi S, Mccracken LM. Preliminary investigation of self-as-context in people with fibromyalgia. $\mathrm{Br} J$ Pain. 2017;11(3):134-143.

29. Mccracken LM, Yang S-Y. The role of values in a contextual cognitivebehavioral approach to chronic pain. Pain. 2006;123(1):137-145.

30. Vowles KE, Mccracken LM. Acceptance and values-based action in chronic pain: a study of treatment effectiveness and process. J Consult Clin Psychol. 2008;76(3):397-407.

31. Mccracken LM. Committed action: an application of the psychological flexibility model to activity patterns in chronic pain. J Pain. 2013;14(8):828-835.

32. Mccracken LM, Chilcot J, Norton S. Further development in the assessment of psychological flexibility: a shortened Committed Action Questionnaire (CAQ-8). Eur J Pain. 2015;19(5):677-685.

33. Hann KEJ, McCracken LM. A systematic review of randomized controlled trials of acceptance and commitment therapy for adults with chronic pain: outcome domains, design quality, and efficacy. $J$ Contextual Behav Sci. 2014;3(4):217-227.

34. Veehof MM, Trompetter HR, Bohlmeijer ET, Schreurs KMG. Acceptance- and mindfulness-based interventions for the treatment of chronic pain: a meta-analytic review. Cogn Behav Ther. 2016;45(1):5-31.

35. Hughes LS, Clark J, Colclough JA, Dale E, Mcmillan D. Acceptance and commitment therapy (ACT) for chronic pain: a systematic review and meta-analyses. Clin J Pain. 2017;33:552-568.

36. Öst L-G. The efficacy of acceptance and commitment therapy: an updated systematic review and meta-analysis. Behav Res Ther. 2014;61:105-121.

37. Atkins PWB, Ciarrochi J, Gaudiano BA, et al. Departing from the essential features of a high quality systematic review of psychotherapy: a response to Öst (2014) and recommendations for improvement. Behav Res Ther. 2017;97:259-272.

38. Öst L-G. Rebuttal of Atkins et al. (2017) critique of the Öst (2014) meta-analysis of ACT. Behav Res Ther. 2017;97:273-281.

39. Fernández E, Salem D, Swift JK, Ramtahal N. Meta-analysis of dropout from cognitive behavioral therapy: magnitude, timing, and moderators. J Consult Clin Psychol. 2015;83(6):1108-1122.

40. Ong CW, Lee EB, Twohig MP. A meta-analysis of dropout rates in acceptance and commitment therapy. Behav Res Ther. 2018;104: 14-33.

41. Drummond MF, Sculpher MJ, Torrance GW, O’Brien BJ, Stoddart GL. Methods for the Economic Evaluation of Health Care Programmes. 3rd ed. Oxford: Oxford University Press; 2005.

42. Haycox A. What Is Health Economics? London, UK: Hayward Medical Communications; 2009.

43. Castelnuovo G, Pietrabissa G, Cattivelli R, Manzoni GM, Molinari E. Not only clinical efficacy in psychological treatments: clinical psychology must promote cost-benefit, cost-effectiveness, and costutility analysis. Front Psychol. 2016;7(27):563.

44. Feliu-Soler A, Cebolla A, Mccracken LM, et al. Economic impact of third-wave cognitive behavioral therapies: a systematic review and quality assessment of economic evaluations in randomized controlled trials. Behav Ther. 2018;49(1):124-147.

45. Kemani MK, Olsson GL, Lekander M, Hesser H, Andersson E, Wicksell RK. Efficacy and cost-effectiveness of acceptance and commitment therapy and applied relaxation for longstanding pain. Clin J Pain. 2015;31(11):1004-1016.

46. Luciano JV, D'Amico F, Feliu-Soler A, et al. Cost-utility of group acceptance and commitment therapy for fibromyalgia versus recommended drugs: an economic analysis alongside a 6-month randomized controlled trial conducted in Spain (EFFIGACT Study). J Pain. 2017;18(7):868-880.

47. Hayes $\mathrm{S}$, Hogan M, Dowd H, et al. Comparing the clinical-effectiveness and cost-effectiveness of an internet-delivered acceptance and commitment therapy (ACT) intervention with a waiting list control among adults with chronic pain: study protocol for a randomised controlled trial. BMJ Open. 2014;4(7):e005092.
48. Lin J, Lüking M, Ebert DD, Buhrman M, Andersson G, Baumeister $H$. Effectiveness and cost-effectiveness of a guided and unguided internet-based acceptance and commitment therapy for chronic pain: study protocol for a three-armed randomised controlled trial. Internet Interv. 2015;2(1):7-16.

49. Kraemer HC, Wilson GT, Fairburn CG, Agras WS. Mediators and moderators of treatment effects in randomized clinical trials. Arch Gen Psychiatry. 2002;59(10):877-883.

50. Turner JA, Holtzman S, Mancl L. Mediators, moderators, and predictors of therapeutic change in cognitive-behavioral therapy for chronic pain. Pain. 2007;127:276-286.

51. Wicksell RK, Olsson GL, Hayes SC. Psychological flexibility as a mediator of improvement in acceptance and commitment therapy for patients with chronic pain following whiplash. Eur J Pain 2010;14(10):1059.e1-1059.e11.

52. Mccracken LM, Morley S. The psychological flexibility model: a basis for integration and progress in psychological approaches to chronic pain management. J Pain. 2014;15(3):221-234.

53. Mccracken LM, Vowles KE. Acceptance and commitment therapy and mindfulness for chronic pain: model, process, and progress. $\mathrm{Am}$ Psychol. 2014;69(2):178-187.

54. Lin J, Klatt L-I, Mccracken LM, Baumeister H. Psychological flexibility mediates the effect of an online-based acceptance and commitment therapy for chronic pain. Pain. 2018;159(4):663-672.

55. Bendayan R, Esteve R, Blanca MJ. New empirical evidence of the validity of the Chronic Pain Acceptance Questionnaire: the differential influence of activity engagement and pain willingness on adjustment to chronic pain. Br J Health Psychol. 2012;17(2):314-326.

56. Mccracken LM, Velleman SC. Psychological flexibility in adults with chronic pain: a study of acceptance, mindfulness, and values-based action in primary care. Pain. 2010;148(1):141-147.

57. Steiner JL, Bogusch L, Bigatti SM. Values-based action in fibromyalgia: Results from a randomized pilot of acceptance and commitment therapy. Health Psychol Res. 2013;1(3):e34.

58. Cederberg JT, Cernvall M, Dahl J, von Essen L, Ljungman G. Acceptance as a mediator for change in acceptance and commitment therapy for persons with chronic pain? Int J Behav Med. 2016;23(1):21-29.

59. Vowles KE, Witkiewitz K, Sowden G, Ashworth J. Acceptance and commitment therapy for chronic pain: evidence of mediation and clinically significant change following an abbreviated interdisciplinary program of rehabilitation. J Pain. 2014;15(1):101-113.

60. Åkerblom S, Perrin S, Rivano Fischer M, Mccracken LM. The mediating role of acceptance in multidisciplinary cognitive-behavioral therapy for chronic pain. J Pain. 2015;16(7):606-615.

61. Mccracken LM, Gutiérrez-Martínez O, Smyth C. "Decentering" reflects psychological flexibility in people with chronic pain and correlates with their quality of functioning. Health Psychology. 2013;32(7):820-823.

62. Daly-Eichenhardt A, Scott W, Howard-Jones M, Nicolaou T, Mccracken LM. Changes in sleep problems and psychological flexibility following interdisciplinary acceptance and commitment therapy for chronic pain: an observational cohort study. Front Psychol. 2016;7(CD007407):1326.

63. Scott W, Hann KEJ, Mccracken LM. A comprehensive examination of changes in psychological flexibility following acceptance and commitment therapy for chronic pain. J Contemp Psychother. 2016;46(3):139-148.

64. Bramwell K, Richardson T. Improvements in depression and mental health after acceptance and commitment therapy are related to changes in defusion and values-based action. J Contemp Psychother. 2018;48(1):9-14.

65. Scott W, Mccracken LM, Norton S. A confirmatory factor analysis of facets of psychological flexibility in a sample of people seeking treatment for chronic pain. Ann Behav Med. 2016;50(2):285-296.

66. Vowles KE, Sowden G, Ashworth J. A comprehensive examination of the model underlying acceptance and commitment therapy for chronic pain. Behav Ther. 2014;45(3):390-401.

67. Hayes SC, Villatte M, Levin M, Hildebrandt M. Open, aware, and active: contextual approaches as an emerging trend in the behavioral and cognitive therapies. Ann Rev Clin Psychol. 2011;7(1):141-168. 
68. Mccracken LM, Turk DC. Behavioral and cognitive behavioral treatment for chronic pain: outcome, predictors of outcome, and treatment process. Spine. 2002;27:2564-2573.

69. Mccracken LM, Mackichan F, Eccleston C. Contextual cognitive-behavioral therapy for severely disabled chronic pain sufferers: effectiveness and clinically significant change. Eur J Pain. 2007;11(3):314-322.

70. Wetherell JL, Petkus AJ, Alonso-fernández M, Bower ES, Steiner ARW, Afari N. Age moderates response to acceptance and commitment therapy vs. cognitive behavioral therapy for chronic pain. Int J Geriatr Psychiatry. 2016;31(3):302-308.

71. Davis MC, Zautra AJ, Wolf LD, Tennen H, Yeung EW. Mindfulness and cognitive-behavioral interventions for chronic pain: differential effects on daily pain reactivity and stress reactivity. J Consult Clin Psychol. 2015;83(1):24-35.

72. Gilpin HR, Keyes A, Stahl DR, Greig R, Mccracken LM. Predictors of treatment outcome in contextual cognitive and behavioral therapies for chronic pain: a systematic review. J Pain. 2017;18(10):1153-1164.

73. Jensen KB, Kosek E, Wicksell R, et al. Cognitive behavioral therapy increases pain-evoked activation of the prefrontal cortex in patients with fibromyalgia. Pain. 2012;153(7):1495-1503.

74. Smallwood RF, Potter JS, Robin DA. Neurophysiological mechanisms in acceptance and commitment therapy in opioid-addicted patients with chronic pain. Psychiatry Res. 2016;250:12-14.

75. Hayes SC, Follette VM, Linehan M. Mindfulness and Acceptance: Expanding the Cognitive-Behavioral Tradition. New York: Guilford Press; 2004.

76. Hölzel BK, Carmody J, Vangel M, et al. Mindfulness practice leads to increases in regional brain gray matter density. Psychiatry Res. 2011;191(1):36-43.

77. Marchand WR. Neural mechanisms of mindfulness and meditation: evidence from neuroimaging studies. World J Radiol. 2014;6(7):471-479.

78. Chiesa A, Serretti A, Jakobsen JC. Mindfulness: top-down or bottomup emotion regulation strategy? Clin Psychol Rev. 2013;33(1):82-96.

79. Zeidan F, Martucci KT, Kraft RA, Gordon NS, Mchaffie JG, Coghill RC. Brain mechanisms supporting the modulation of pain by mindfulness meditation. J Neurosci. 2011;31(14):5540-5548.

80. Kallesøe KH, Schröder A, Wicksell RK, Fink P, Ørnbøl E, Rask CU. Comparing group-based acceptance and commitment therapy (ACT) with enhanced usual care for adolescents with functional somatic syndromes: a study protocol for a randomised trial. BMJ Open. 2016;6(9):e012743.

81. Institute of Medicine (US) Committee on Advancing Pain Research, Care, and Education. Relieving Pain in America: A Blueprint for Transforming Prevention, Care, Education, and Research. Washington: National Academies Press (US); 2011.

82. Mafi JN, Mccarthy EP, Davis RB, Landon BE. Worsening trends in the management and treatment of back pain. JAMA Intern Med. 2013;173(17):1573-1581.

83. Chou R, Fanciullo GJ, Fine PG, et al. Clinical guidelines for the use of chronic opioid therapy in chronic noncancer pain. J Pain. 2009;10(2):113-130.

84. Becker WC, Dorflinger L, Edmond SN, Islam L, Heapy AA, Fraenkel L. Barriers and facilitators to use of non-pharmacological treatments in chronic pain. BMC Fam Pract. 2017;18(1):41.

85. Mottram S, Peat G, Thomas E, Wilkie R, Croft P. Patterns of pain and mobility limitation in older people: cross-sectional findings from a population survey of 18,497 adults aged 50 years and over. Qual Life Res. 2008;17(4):529-539.

86. Mccracken LM, Sato A, Taylor GJ. A trial of a brief group-based form of acceptance and commitment therapy (ACT) for chronic pain in general practice: pilot outcome and process results. J Pain. 2013;14(11):1398-1406.

87. Herbert MS, Afari N, Liu L, et al. Telehealth versus in-person acceptance and commitment therapy for chronic pain: a randomized noninferiority trial. J Pain. 2017;18(2):200-211.
88. Scott W, Chilcot J, Guildford B, Daly-Eichenhardt A, Mccracken LM. Feasibility randomized-controlled trial of online acceptance and commitment therapy for patients with complex chronic pain in the United Kingdom. Eur J Pain. 2018;22(8):1473-1484.

89. Simister HD, Tkachuk GA, Shay BL, Vincent N, Pear JJ, Skrabek RQ. Randomized controlled trial of online acceptance and commitment therapy for fibromyalgia. J Pain. 2018;19(7):741-753.

90. Yang S-Y, Moss-Morris R, Mccracken LM. iACT-CEL: a feasibility trial of a face-to-face and internet-based acceptance and commitment therapy intervention for chronic pain in Singapore. Pain Res Treat. 2017;2017(3):6916915-14.

91. Luoma JB, Hayes SC, Walser RD. Learning ACT: An Acceptance \& Commitment Therapy Skills-Training Manual for Therapists. Oakland: New Harbinger \& Reno, NV: Context Press. 2007.

92. Luoma JB, Vilardaga JP. Improving therapist psychological flexibility while training acceptance and commitment therapy: a pilot study. Cogn Behav Ther. 2013;42(1):1-8.

93. Trompetter HR, Schreurs KMG, Heuts PHTG, Vollenbroek-Hutten MM. The systematic implementation of acceptance \& commitment therapy (ACT) in Dutch multidisciplinary chronic pain rehabilitation. Patient Educ Couns. 2014;96(2):249-255.

94. Demarzo MMP, Cebolla A, Garcia-Campayo J. The implementation of mindfulness in healthcare systems: a theoretical analysis. Gen Hosp Psychiatry. 2015;37(2):166-171.

95. Bower P, Gilbody S. Stepped care in psychological therapies: access, effectiveness and efficiency: narrative literature review. Br J Psychiatry. 2005;186:11-17.

96. Hill JC, Whitehurst DGT, Lewis M, et al. Comparison of stratified primary care management for low back pain with current best practice (STarT Back): a randomised controlled trial. Lancet. 2011;378(9802):1560-1571.

97. Burns JW. Mechanisms, mechanisms, mechanisms: it really does all boil down to mechanisms. Pain. 2016;157(11):2393-2394.

98. Andrew Moore R. What works for whom? Determining the efficacy and harm of treatments for pain. Pain. 2013;154:S77-S86.

99. Vlaeyen JW, Morley S. Cognitive-behavioral treatments for chronic pain: what works for whom? Clin J Pain. 2005;21:1-8.

100. Eccleston C, Hearn L, Williams A. Psychological therapies for the management of chronic neuropathic pain in adults. Cochrane Database Syst Rev. 2015;10:CD011259.

101. Gregg JA, Callaghan GM, Hayes SC, Glenn-Lawson JL. Improving diabetes self-management through acceptance, mindfulness, and values: a randomized controlled trial. J Consult Clin Psychol. 2007;75(2):336-343.

102. Lillis J, Kendra KE. Acceptance and commitment therapy for weight control: model, evidence, and future directions. J Contextual Behav Sci. 2014;3(1):1-7.

103. Masuda A, Hill ML, Morgan J, Cohen LL. A psychological flexibilitybased intervention for modulating the impact of stigma and prejudice: a descriptive review of empirical evidence. Psychol Soc Educ. 2012;4(2):211-223.

104. Nam SL, Fielding K, Avalos A, Dickinson D, Gaolathe T, Geissler PW. The relationship of acceptance or denial of HIV-status to antiretroviral adherence among adult HIV patients in urban Botswana. Soc Sci Med. 2008;67(2):301-310.

105. Skinta MD, Lezama M, Wells G, Dilley JW. Acceptance and compassion-based group therapy to reduce HIV stigma. Cog Behav Pract. 2015;22(4):481-490.

106. Francis AW, Dawson DL, Golijani-Moghaddam N. The development and validation of the Comprehensive assessment of Acceptance and Commitment Therapy processes (CompACT). J Contextual Behav Sci. 2016;5(3):134-145.

107. Gloster AT, Klotsche J, Ciarrochi J, et al. Increasing valued behaviors precedes reduction in suffering: findings from a randomized controlled trial using ACT. Behav Res Ther. 2017;91:64-71. 
108. Gloster AT, Miché M, Wersebe H, et al. Daily fluctuation of emotions and memories thereof: design and methods of an experience sampling study of major depression, social phobia, and controls. Int J Methods Psychiatr Res. 2017;26(3):e1578.

109. Turner JA, Anderson ML, Balderson BH, Cook AJ, Sherman KJ, Cherkin DC. Mindfulness-based stress reduction and cognitive behavioral therapy for chronic low back pain: similar effects on mindfulness, catastrophizing, self-efficacy, and acceptance in a randomized controlled trial. Pain. 2016;157(11):2434-2444.

110. Hayes SC, Hofmann SG. The third wave of cognitive behavioral therapy and the rise of process-based care. World Psychiatry. 2017;16(3):245-246.
111. McMillan D, Morley S. Single case quantitative methods for practicebased evidence. Developing and Delivering Practice-Based Evidence: A Guide for the Psychological Therapies. Barkham M, Hardy GE, MellorClark J, editors. Chichester, UK: John Wiley \& Sons; 2010:109-138.

112. Godfrey E, Galea Holmes M, Wileman V, et al. Physiotherapy informed by acceptance and commitment therapy (PACT): protocol for a randomised controlled trial of PACT versus usual physiotherapy care for adults with chronic low back pain. BMJ Open. 2016;6(6):e011548.

113. Eccleston C, Fisher E, Craig L, Duggan GB, Rosser BA, Keogh E. Psychological therapies (internet-delivered) for the management of chronic pain in adults. Cochrane Database Syst Rev. 2014;2(2):CD010152.
Journal of Pain Research

\section{Publish your work in this journal}

The Journal of Pain Research is an international, peer reviewed, open access, online journal that welcomes laboratory and clinical findings in the fields of pain research and the prevention and management of pain. Original research, reviews, symposium reports, hypothesis formation and commentaries are all considered for publication

\section{Dovepress}

The manuscript management system is completely online and includes a very quick and fair peer-review system, which is all easy to use. Visit http://www.dovepress.com/testimonials.php to read real quotes from published authors. 